\title{
Influence of V Precipitates on Acicular Ferrite Transformation Part 2: Transformation Kinetics
}

\author{
Carlos GARCIA-MATEO, Juan CORNIDE, Carlos CAPDEVILA, Francisca G. CABALLERO and \\ Carlos Garcia de ANDRÉS
}

MATERALIA Research Group, Department of Physical Metallurgy, Centro Nacional de Investigaciones Metalúrgicas (CENIM), Consejo Superior de Investigaciones Científicas (CSIC), Avda. Gregorio del Amo, 8. E-28040 Madrid, Spain.

E-mail: cgm@cenim.csic.es.

(Received on February 25, 2008; accepted on June 3, 2008)

\begin{abstract}
A combination of thermodynamic models as well as some physical metallurgical principles has been used to analyse the influence that $\mathrm{V}(\mathrm{C}, \mathrm{N})$ precipitates have on the transformation kinetics of acicular ferrite by isothermal decomposition of austenite. Those precipitates were found absolutely necessary for the nucleation of acicular ferrite as reported in Part 1 of this work, now in Part 2, through the proper design of a heat treatment route we have studied the effect that those precipitates have on the kinetics of acicular ferrite transformation.
\end{abstract}

KEY WORDS: acicular ferrite; bainite; $\mathrm{V}(\mathrm{C}, \mathrm{N})$; dilatometry; temperature time transformation diagrams; transformation kinetics.

\section{Introduction}

In part $1^{1)}$ of this two part study it was proven how $\mathrm{N}$ through its combination with $\mathrm{V}$ enhances the formation of $\mathrm{V}(\mathrm{C}, \mathrm{N})$ precipitates within austenite that will act as nucleation sites for acicular ferrite (AF) as long as the austenite grain boundaries are, previously to the transformation, decorated with proeutectoid ferrite. In this part two heat treatment routes were designed on the basis of some thermodynamics and equilibrium criteria, so in one of the two routes precipitation is enhanced while in the other one is not, and a comparative study of the kinetics of AF transformation in both routes allow us to analyse the role that the aforementioned precipitates are playing.

\section{Materials and Experimental Procedure}

The chemical composition of the alloy used is listed in Table 1, denoted as 5B steel in part 1. ${ }^{1)}$

An Adamel Lhomargy DT1000 high resolution dilatometer has been used to determine the TTT diagrams of the steels, and to track the evolution of AF transformation.

Cylindrical dilatometric specimens of $2 \mathrm{~mm}$ diameter and $12 \mathrm{~mm}$ length were austenitised and then isothermally transformed at different temperatures until transformation was completed followed by gas quenching to room temper-

Table 1. Chemical composition of the experimental grade, in $\mathrm{wt} \%$.

\begin{tabular}{cccccccccc}
\hline & $\mathrm{C}$ & $\mathrm{Mn}$ & $\mathrm{V}$ & $\mathrm{N}$ & $\mathrm{Al}$ & $\mathrm{Si}$ & $\mathrm{S}$ & $\mathrm{Cr}$ & $\mathrm{Ni}$ \\
\hline 5B & 0.08 & 1.46 & 0.25 & 0.018 & 0.016 & 0.007 & 0.001 & 0.01 & 0.009 \\
\hline
\end{tabular}

ature. A simple lever rule based method allow us estimating the evolution of the normalized volume fraction of AF $V_{\mathrm{AF}} / V_{\mathrm{AF}}^{\max }$ with time from the recording of the change in length of the specimen during transformation, a method that has been previously validated in Ref. 2).

$$
\frac{V_{\mathrm{AF}}}{V_{\mathrm{AF}}^{\max }}=\frac{L(t)-L_{0}}{L_{\mathrm{f}}-L_{0}}
$$

where $V_{\mathrm{AF}}^{\max }$ is the maximum volume fraction of $\mathrm{AF}$ formed at the end of the isothermal reaction, $L(t), L_{0}$ and $L_{\mathrm{f}}$ are the lengths of the specimen at $t$, just before the beginning and right at the end of transformation respectively.

Specimens were polished and etched in the usual way for further metallographic examination by means of optical and field emission gun scanning electron microscopy. The previous austenite grain boundary was revealed by means of the thermal etching technique. ${ }^{3)}$

A set of theoretical calculations concerning temperature evolution of different phases present, as well as bainite start temperature $\left(\mathrm{B}_{\mathrm{S}}\right)$ were performed with the help of a commercial package for thermodynamic calculations in equilibrium in combination with the SGSOL-SGTE Solution database $3.0 .^{4)}$

Thermoelectric power measurements (TEP) were performed to experimentally estimate the level of $\mathrm{V}(\mathrm{C}, \mathrm{N})$ precipitation. TEP measurements are based on Seebeck effect, thus, a difference in the temperature at both extremes of the sample creates a potential difference $\Delta V$, the relative TEP is given by $\Delta S=\Delta V / \Delta T$. Restoration, recrystallisation and precipitation processes increase $\Delta S$ values, while cold working (increase of dislocation density) and dissolution processes decrease $\Delta S$. For these experiments, $30 \times 2 \times$ 
$0.8 \mathrm{~mm}^{3}$ samples were machined longitudinally to the rolling direction. A schematic representation of the TEP apparatus and further detail on the theory lying beneath this technique is given elsewhere. ${ }^{5)}$

The martensite start temperature $\left(\mathrm{M}_{\mathrm{S}}\right)$ of the steel was determined by dilatometry, where standard cylindrical specimens were austenitised and then rapidly cooled. Martensite formation during cooling was detected by monitoring the fractional change in dilatation with temperature, to ensure reliability of the result the test was performed at least twice.

\section{Results and Discussion}

Figure 1 shows the two routes designed and adopted in this work to analyze the influence of $\mathrm{V}(\mathrm{C}, \mathrm{N})$ precipitates on AF transformation kinetics. Route 2 was designed to have a higher fraction of potent nucleation sites for AF formation compared to Route 1, as it will become clear in the following paragraphs.

Several are the reasons for the selection of $1125^{\circ} \mathrm{C}$ for $120 \mathrm{~s}$ as the austenitising conditions, first is that according to Fig. 2, at this temperature the microstructure is austenite, avoiding the interference of other phases in the study. The second is that according also to Fig. 2, there is a small percentage of $\mathrm{V}$ precipitates present in the microstructure, those together with the small fraction expected to precipitate within austenite during quenching, $500^{\circ} \mathrm{C} / \mathrm{s}$, to the isothermal transformation temperature leaves an austenite with a scarce level of potent nucleation sites for AF formation, case of Route 1. It is also very important, the fact that at this temperature the measured austenite grain size is

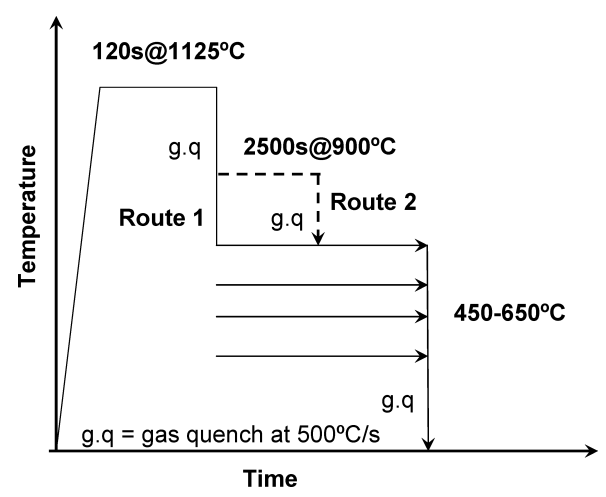

Fig. 1. Heat treatments routes adopted to study the influence of $\mathrm{V}(\mathrm{C}, \mathrm{N})$ on $\mathrm{AF}$ transformation kinetics.

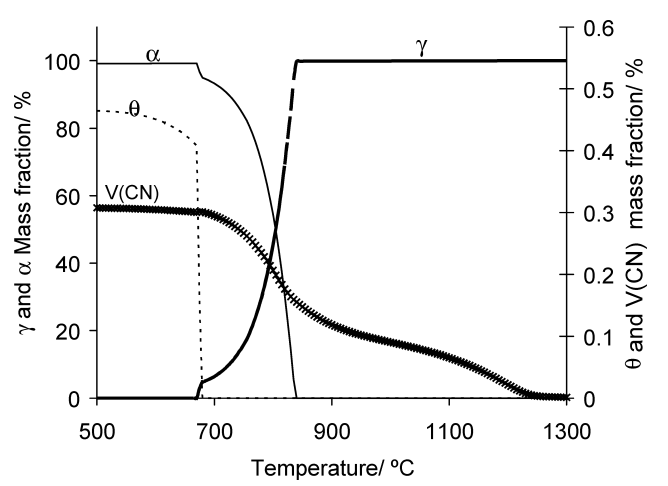

Fig. 2. Calculated equilibrium mass fractions of austenite $(\gamma)$, ferrite $(\alpha)$, cementite $(\theta)$ and $\mathrm{V}(\mathrm{C}, \mathrm{N})$ precipitates.
$60 \mu \mathrm{m}$, i.e. such a big grain size is expected to enhance AF formation in detriment of bainite by increasing the ratio between intragranular and grain boundary nucleation sites. ${ }^{6,7)}$

In the case of the Route 1 the necessary thermodynamic calculations to estimate the $\mathrm{B}_{\mathrm{S}}$ temperature according to Bhadeshia's theory ${ }^{8)}$ were performed by means of Ref. 4), and the obtained result was $590^{\circ} \mathrm{C}$. The experimental $\mathrm{M}_{\mathrm{S}}$ temperature was obtained by dilatometry giving an average value of $480^{\circ} \mathrm{C}$.

In the case of Route 2 a more profuse $\mathrm{V}(\mathrm{C}, \mathrm{N})$ precipitation in austenite is intended, therefore, following austenitisation, samples were quenched at $500^{\circ} \mathrm{C} / \mathrm{s}$ down to $900^{\circ} \mathrm{C}$ and held for $2500 \mathrm{~s}$. The dilatometric curve $\Delta l / l_{0}$ vs. $t$ revealed an Avrami type shape that reached a plateau, at about 2200-2 $400 \mathrm{~s}$, meaning that at $2500 \mathrm{~s}$ the equilibrium conditions described in Fig. 2 has been reached, i.e. about $0.1 \%$ of $\mathrm{V}(\mathrm{C}, \mathrm{N})$ precipitates. Therefore the level of precipitation in austenite is representatively higher than that obtained solely by austenitisation at $1125^{\circ} \mathrm{C}$, Route 1 . To further assess this asseveration a set of TEP measurements were performed on quenched samples that were held at $900^{\circ} \mathrm{C}$ for different periods of time, 5 to $2500 \mathrm{~s}$, after applying the selected austenitisation conditions. Figure 3 shows the relative TEP values measured, where the reference condition for the relative values was a sample that after austenitisation was quenched to room temperature, i.e. corresponding to the level of precipitation attained in Route 1. Giving the fact that the only metallurgical difference between the reference microstructure and that after holding at $900^{\circ} \mathrm{C}$ is the level of precipitation, it is reasonable to assure that any increment in the relative TEP measurements, as the holding time at $900^{\circ} \mathrm{C}$ is increased, can only be justified in terms of an increasing precipitation level. Also Fig. 3 shows that based on EDX analysis the precipitates can be identified as $\mathrm{N}$ rich $\mathrm{V}(\mathrm{C}, \mathrm{N})$ after following Route 2 but quench-
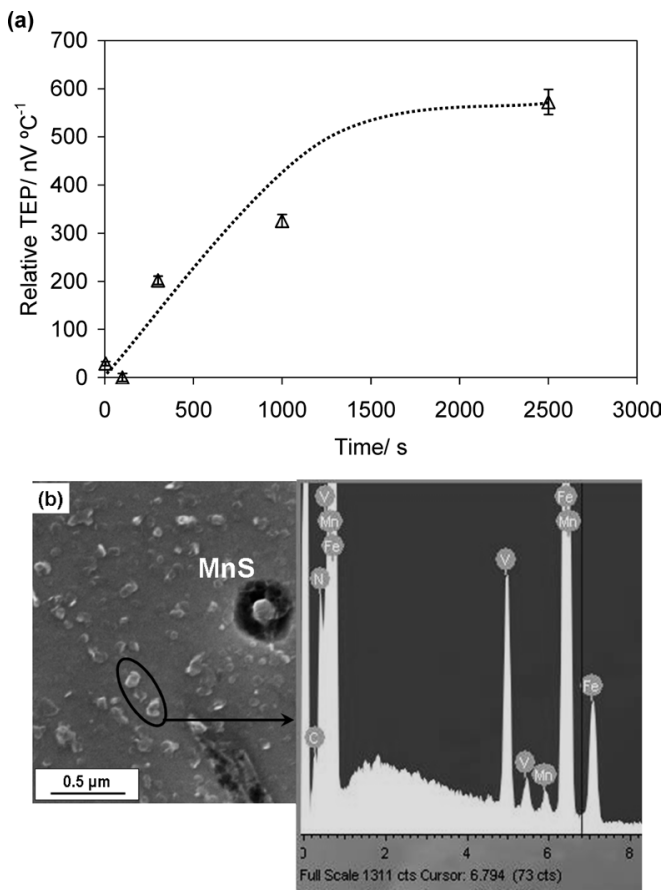

Fig. 3. (a) Evolution of thermoelectric power at $900^{\circ} \mathrm{C}$ as function of holding time at $900^{\circ} \mathrm{C}$. And (b) identification of precipitates at $2500 \mathrm{~s}$ as $\mathrm{V}(\mathrm{C}, \mathrm{N})$. 
ing to room temperature after the isothermal treatment at $900^{\circ} \mathrm{C}-2500 \mathrm{~s}$.

As it was mentioned, given that $2500 \mathrm{~s}$ at $900^{\circ} \mathrm{C}$ allow to reach the equilibrium conditions, new calculations to estimate the $\mathrm{B}_{\mathrm{S}}$ of impoverished austenite in $\mathrm{C}, \mathrm{V}$ and $\mathrm{N}$, once precipitation has been considered as in Fig. 2, were performed as previously described. The results showed a negligible variation of $\mathrm{B}_{\mathrm{S}}$ as compare to that of Route 1 . But in the case of the $M_{S}$ temperature, much more sensitive to austenite C content, ${ }^{9)}$ a slight increase is expected. This point was confirmed by means of dilatometry measurements by quenching to room temperature after $2500 \mathrm{~s}$ at $900^{\circ} \mathrm{C}$, providing with a $\mathrm{M}_{\mathrm{S}}$ average value of $520^{\circ} \mathrm{C}$.

Therefore the selected temperatures for the isothermal heat treatments in both routes were in the range between 650 and $450^{\circ} \mathrm{C}$, at intervals of $25^{\circ} \mathrm{C}$. All the tests were carried out until the dilatometry signal showed that the tracked transformation had ceased, then gas quench to room temperature was applied.

For Routes 1 and 2 martensite is identified at temperatures equal and lower than 475 and $500^{\circ} \mathrm{C}$, respectively, so the $\mathrm{M}_{\mathrm{S}}$ temperature for Route 1 is expected between $475-500^{\circ} \mathrm{C}$ and for Route 2 between $500-525^{\circ} \mathrm{C}$, very similar values to those obtained in the previous dilatometric measurements, 480 and $520^{\circ} \mathrm{C}$ respectively. Figures 4(a) and 4(f) show examples of the microstructure obtained below $\mathrm{M}_{\mathrm{S}}$ for both routes, the profuse precipitation that can be observed is due to a self-tempering process since samples were held more time than strictly necessary to complete the martensitic transformation.

On the other hand AF, were detected for Route 1 between $500-575^{\circ} \mathrm{C}$, see e.g. Figs. 4(b) to 4(d), and for Route 2 between $525-575^{\circ}$ C, Figs. $4(\mathrm{~g})$ to $4(\mathrm{i})$. In Fig. $4(\mathrm{~g})$ it is also possible to observe a lot of small white round features, see e.g. those within the dotted white circle, that were identified as $\mathrm{V}(\mathrm{C}, \mathrm{N}),{ }^{1,10)}$ when comparing with e.g. Fig. 4(c), so it is possible to confirm that effectively Route 2 has promoted $\mathrm{V}$ rich precipitates. Also in Fig. 4(g) it has been pointed the occurrence of cementite precipitation, which is part of the austenite to AF/bainite transformation process when the steel composition does not contain $\mathrm{Si}$ in enough quantities. ${ }^{8)}$ Figures 4(c) and 4(h) show examples of what it seems to be a set of AF plates growing in opposite directions, a clear example of the absolutely random distribution of $\mathrm{AF}$ plates in opposition to the more parallel exhibited by bainite. In both cases it was impossible to identify the precipitate where they nucleated, but it is necessary to remember that this is a planar section of a $3 \mathrm{D}$ microstructure. A more general view of chaotic distribution of AF plates is shown in Fig. 4(d). It is also obvious from the micrographs presented that the AF plates tend to be thinner as the transformation temperature decreases, this is due to the fact that both austenite strength and driving force for the transformation increase by lowering the transformation temperature, therefore there is a larger resistance to interface motion and an increased nucleation rate, leading to smaller plate thickness. ${ }^{11)}$

A remarkable feature in both routes is the total absence of grain boundary ferrite in order to obtain AF, this proeutectoid ferrite was proved to be absolutely necessary to form $\mathrm{AF}$ under the anisothermal heat treatments described
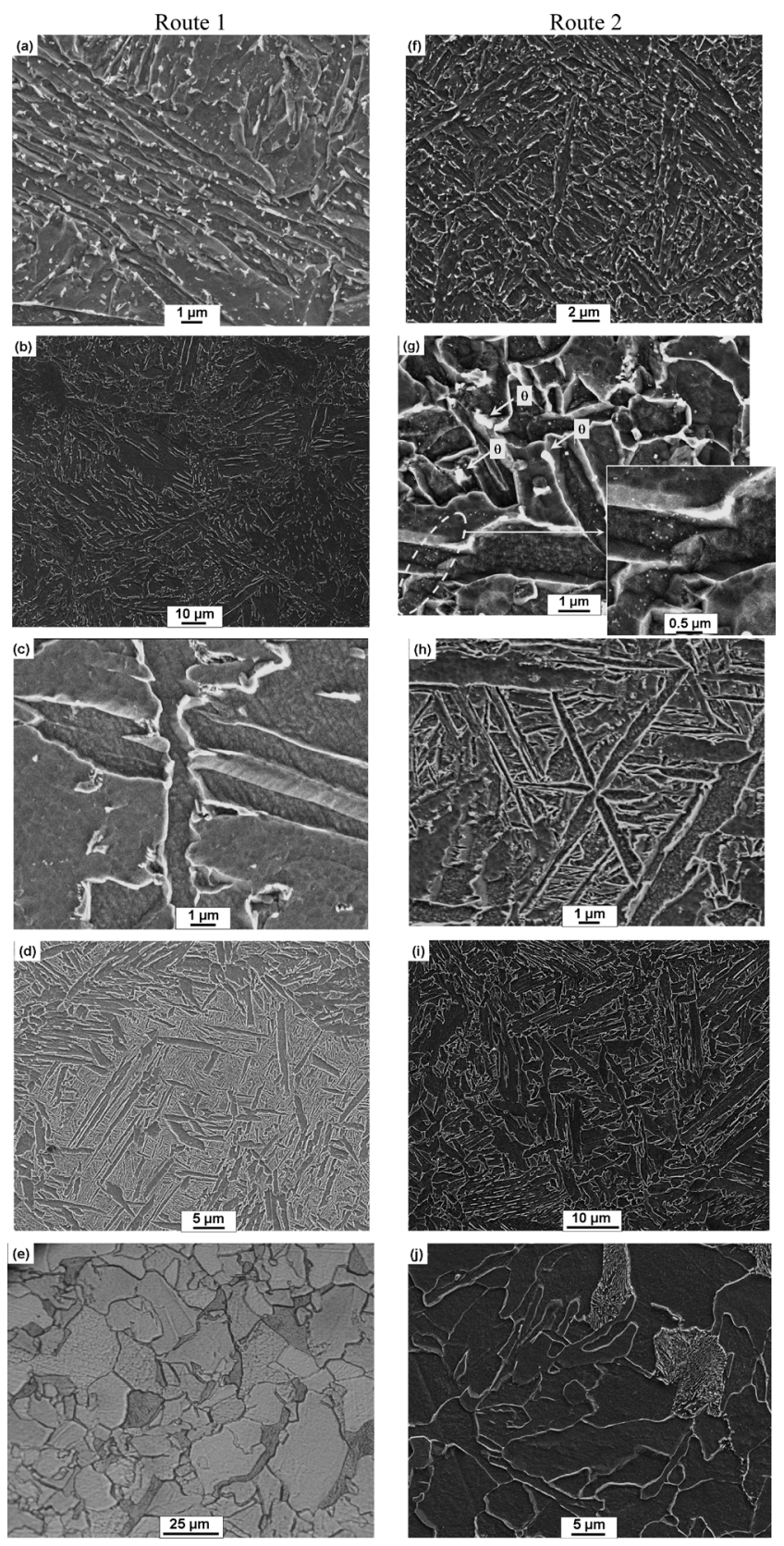

Fig. 4. Micrographs showing some examples of microstructures achieved after different isothermal heat treatments. Thus, for Route 1 (a) $450^{\circ} \mathrm{C}$, (b) $525^{\circ} \mathrm{C}$, (c) $550^{\circ} \mathrm{C}$, (d) $575^{\circ} \mathrm{C}$ and (e) $675^{\circ} \mathrm{C}$, for Route 2 (f) $500^{\circ} \mathrm{C}$, (g) $525^{\circ} \mathrm{C}$, (h) $550^{\circ} \mathrm{C}$, (i) $575^{\circ} \mathrm{C}$ and (j) $650^{\circ} \mathrm{C}$.

in the first part of this work, ${ }^{1)}$ which shows the high effectiveness of the $\mathrm{V}(\mathrm{C}, \mathrm{N})$ particles inside the austenite matrix as intragranular nucleation sites for AF.

Finally in the temperature range between $600-650^{\circ} \mathrm{C}$, for both routes, the observed microstructure is mainly proeutectoid ferrite with some pearlite as the micrographs in Figs. 4(e) and 4(j) reveal. Therefore from the above results it is possible to set the $B_{S}$ temperature for both routes between $575-600^{\circ} \mathrm{C}$ which is in good agreement with the calculated value of $580^{\circ} \mathrm{C}$.

With the help of those results in conjunction with the dilatometric analysis it is possible to outline the TTT diagrams for both routes and the results thus obtained are presented in Fig. 5. It is interesting to note that in the region of interest for this study, AF region, no big differences in 

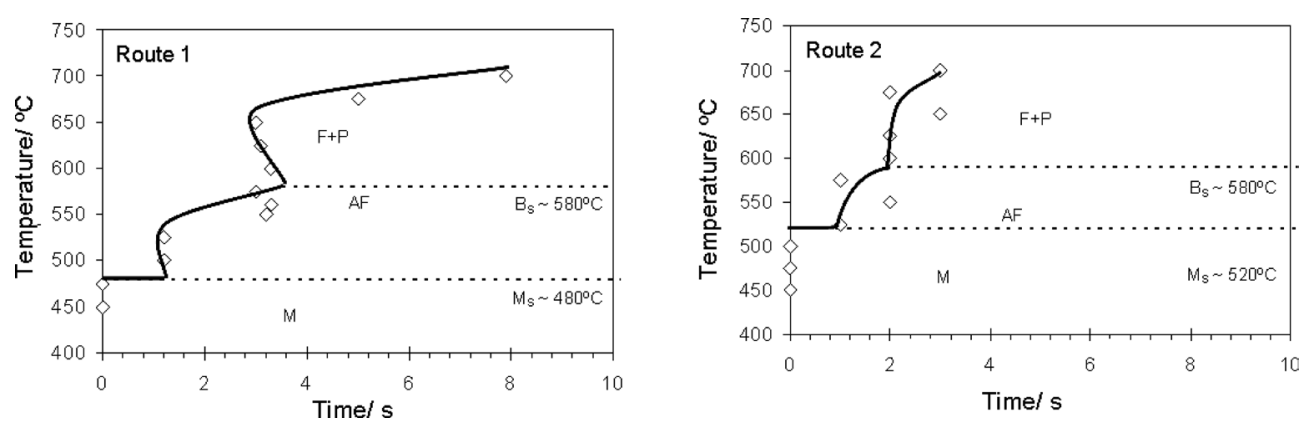

Fig. 5. TTT diagrams for both routes, the error is $\pm 1 \mathrm{~s}$ which is the dilatometer resolution. $\mathrm{F}=$ ferrite, $\mathrm{P}=$ pearlite, $\mathrm{M}=$ martensite, $\mathrm{AF}=$ acicular ferrite.
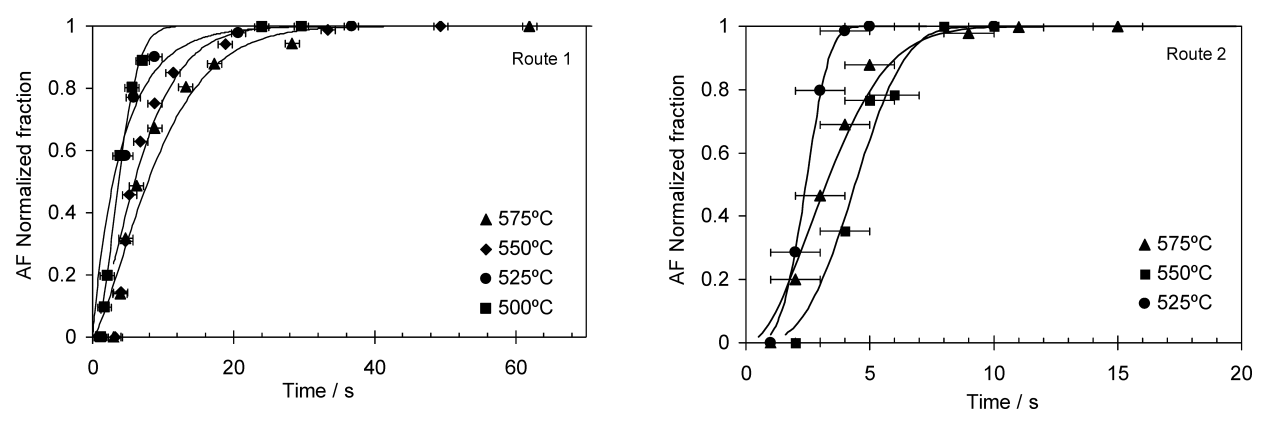

Fig. 6. Experimental results for the overall transformation kinetics of AF. Beware of different time scales.

terms of transformation kinetics are found, for both routes the beginning of AF transformation takes place in just few seconds. It is necessary a more detailed analysis of the dilatometric curves to appreciate the differences introduced by an increasing presence of $\mathrm{V}(\mathrm{C}, \mathrm{N})$ precipitates. Thus, making use of Eq. (1) it is possible to sketch the overall transformation kinetics of AF for Route 1 and 2 as the time evolution of estimated normalized fraction, $V_{\mathrm{AF}} / V_{\mathrm{AF}}^{\max }$, see Fig. 6. As it has been just mentioned the beginning of transformation for both routes is very similar, about $1-2 \mathrm{~s}$, but this is not the case for the end of it. While for Route 2 the end of transformation is detected in between 5 and $15 \mathrm{~s}$ for Route 1 is in the range of 30 to $60 \mathrm{~s}$. Therefore the results allows us to indicate that, indeed the more profuse presence of $\mathrm{V}(\mathrm{C}, \mathrm{N})$ precipitates in Route 2 leads to an AF transformation kinetics that is much faster than that detected for conditions in Route 1, where the precipitation of such particles is scarcer.

\section{Conclusions}

In this work two different routes were design so the effect of $\mathrm{V}(\mathrm{C}, \mathrm{N})$ precipitates on acicular ferrite formation could be analyzed. To avoid the formation of bainite instead of acicular ferrite, the selected previous austenite grain size was $60 \mu \mathrm{m}$, big enough to ensure the reduction of bainite nucleation sites and, at the same time increasing the probability of trapping more of those precipitates within. Then two heat treatment routes were designed, in one of them precipitation of $\mathrm{V}(\mathrm{C}, \mathrm{N})$ is enhanced by applying after austenitisation, a precipitation isothermal treatment at $900^{\circ} \mathrm{C}$ (austenite field) during $2500 \mathrm{~s}$. Given the fact that the only difference between both routes is the amount of precipitates in austenite, the observed acceleration of acicular ferrite transformation kinetics, in the route where pro- fuse precipitation took place as compared with the other one, can only be explained in terms that $\mathrm{V}(\mathrm{C}, \mathrm{N})$ precipitates effectively enhance acicular ferrite formation by strongly increasing the ratio between intragranular and grain boundary nucleation sites.

\section{Acknowledgements}

The authors would like to acknowledge the Commission of the European Communities for the financial support in the frame of the RFCS Programme for 2004 (RFS-PR03136). Also to the Spanish MCYT through the project MAT2005-24485-E. The authors are extremely grateful to J. Vara for his support in the experimental part of this work.

\section{REFERENCES}

1) C. Garcia-Mateo, C. Capdevila, F. G. Caballero, C. G. de Andrés, ISIJ. Int., 48 (2008), 1270.

2) F. G. Caballero, M. J. Santofimia, C. Garcia-Mateo and C. G. de Andres: Mater. Trans. 45 (2004), 3272.

3) C. Garcia de Andrés, F. G. Caballero, C. Capdevila and D. San Martin: Mater. Charact., 49 (2003), 121.

4) MTDATA National Physical Laboratory, Teddington, UK, 2003 at www.npl.co.uk/mtdata/. (access date: August 4, 2008)

5) N. J. A. Luiggi: Metall. Mater. Trans. A, 29A (1998), 2669.

6) C. Capdevila, F. G. Caballero, C. García-Mateo and C. García de Andrés: Mater. Trans. 45 (2004), 2678.

7) C. Capdevila, F. G. Caballero, C. García de Andrés: Mater. Sci. Technol., 19 (2003), 195.

8) H. K. D. H. Bhadeshia: Bainite in Steels, 2nd ed., The Institute of Materials, London, UK, (2001).

9) H. K. D. H. Bhadeshia and R. W. K. Honeycombe: Steels Microstructure and Properties, 3rd ed., The Institute of Materials, London, UK, (2006).

10) B. Donnay, R. Creutz, H. Hild, C. Capdevila Montes, C. GarciaMateo, F. G. Caballero, C. García de Andrés, A. De Ro, C. Stallybrass, O. Karlsson, S. Zajac, L. Ryde and J. Komenda: Technical Report No. 5, REHOMI European Project (RFS-CR-04030), (2006).

11) S. B. Singh and H. K. D. H. Bhadeshia: Mater. Sci. Eng. A, A245 (1998), 72 